\title{
Priority Influence of Horizontal Forces at Rolling on Operation of Main Sheet Rolling Equipment
}

\author{
Viktor Artiukh ${ }^{1, *}$, Vladlen Mazur ${ }^{2}$, and Aleksey Adamtsevich ${ }^{3}$ \\ ${ }^{1}$ Peter the Great St. Petersburg Polytechnic University, Polytechnicheskaya, 29, Saint-Petersburg, \\ 195251, Russia \\ ${ }^{2}$ LLC «Saint-Petersburg Electrotechnical Company», Pushkin, Parkovaya, 56, Saint-Petersburg, \\ 196603, Russia \\ ${ }^{3}$ Moscow State University of Civil Engineering, Yaroslavskoe shosse, 26, Moscow, 129337, Russia
}

\begin{abstract}
Horizontal force during unsteady rolling is considered with its calculation for 4-high rolling stands when rolling torques and rolling stands geometrical characteristics are known. Phenomenon of appearance of horizontal forces applied to work rolls preceding appearance of all other basic loads in sheet rolling mill stands and their main drive lines was theoretically and experimentally proved for different rolling mill stands.
\end{abstract}

\section{Introduction}

Main attention is given to dynamic (unsteady) and static (steady) rolling torques in methods of detailed theoretical stress calculations of main drive lines and scrutinize of dynamic loads in different rolling stands [1-6]. Also, reasons of numerous accidental breakdowns of details of main drive lines are believed to be high values of dynamic rolling torques $[3,7,8]$. At theoretical and experimental studies of horizontal forces during rolling [9-12] main aims were calculation of horizontal forces, increase of equipment durability, improve of quality of rolled metal, etc.

In addition, in modern practice of protection of metallurgical machines from breakdowns it is priority to protect equipment from high values of dynamic rolling torques but question of reduction of horizontal forces during rolling is rarely considered. That is why, main aim of this paper are:

- definition of relation between horizontal forces $F_{\text {hor. }}$ and dynamic rolling torques $T_{d}$ for thick and thin strip 4-hi rolling stands;

- prove that $\mathrm{F}_{\text {hor. }}$ and impacts of work roll (WR) chocks against housings arise earlier than $T_{d}$ that states necessity to analyze $F_{\text {hor. }}$ especially during unsteady rolling.

\section{Materials and Methods}

Act of initial horizontal force from billet on bottom work roll (BWR) is described in [13]. Scheme of act of initial dynamic horizontal force $F_{\text {hor. } d \text { BWR }}$ on the basis of BWR is shown

\footnotetext{
*Corresponding author: artiukh@mail.ru
} 
on Figure 1. It is done for case when forces are moved to the central point of BWR and $\mathrm{F}_{\text {hor. }}$ $\mathrm{d}$ BWR acts from neutral section plane (NSP).
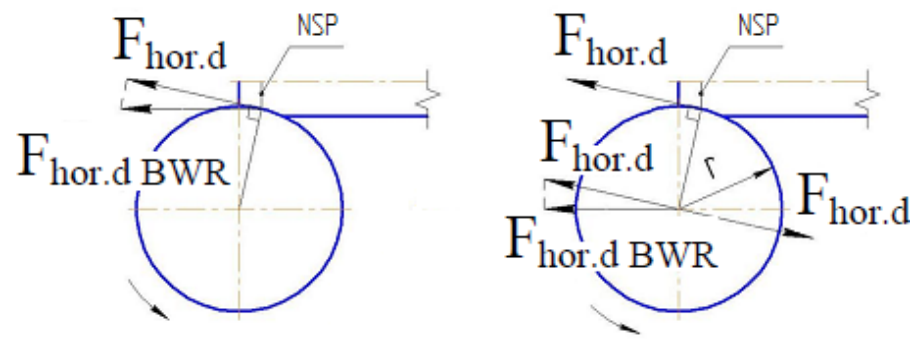

Fig. 1. Scheme of act of initial dynamic horizontal force $F_{\text {hor. } d B W R}$ from metal billet on BWR when it is moved to the central point of BWR.

Taking into consideration calculation of initial horizontal dynamic force on $\mathrm{i}-\mathrm{WR} \mathrm{F}_{\text {hor. }} \mathrm{i}$ for 2-hi rolling stand is shown in [13]. $\mathrm{F}_{\text {hor. } \mathrm{di}}$ can be calculated at period of time t for 4-hi rolling stand (when there is no slippage between WR and back-up roll (BUR)) as per:

$$
F_{\text {hor. di }}(t)=\frac{T_{\mathrm{di}}(t)-T_{s t \mathrm{i}}(t)}{r_{i} \cdot\left[1+\left(\frac{r_{i}}{R_{j}}\right)^{2}\right]}, \mathrm{N}
$$

Where $T_{d i}$ is dynamic rolling torque on $\mathrm{i}-\mathrm{WR}$ (its spindle), $\mathrm{N} \cdot \mathrm{m} ; \mathrm{T}_{\mathrm{st}}$ i is static rolling torque (during steady rolling) on $\mathrm{i}-\mathrm{WR}$ (its spindle), $\mathrm{N} \cdot \mathrm{m} ; \mathrm{r}_{\mathrm{i}}$ is radius of $\mathrm{i}-\mathrm{WR}, \mathrm{m} ; \mathrm{R}_{\mathrm{j}}$ is radius of $\mathrm{j}$-BUR which is in contact with $\mathrm{i}-\mathrm{WR}, \mathrm{m}$.

Further transformation of $F_{\text {hor. di }}$ in dynamic force of horizontal impact of WR chock is described in $[14,15]$. On its value significant influence make:

- horizontal rigidity of housing in place of impact of WR chock (its lining strap) against housing window (its facing strip);

- gap between lining strap and facing strip;

- energy of the impact.

Proposed method of calculation of dynamic horizontal force theoretical value can be used by rolling mills staff.

Experimental data analysis of dynamic rolling torques measurements on spindles, WRs and deformation / elongation of housings frames of hot strip rolling mills 2500 and 1700 [11-12] shows that deformation / elongation of housings frames (by rolling force $\mathrm{P}$ at start of rolling) begins earlier then increase of $T_{D}$ on spindle near WR by around $0.018 \ldots 0.021$ $\mathrm{sec}$ (refer to Figure 2). To the point, maximum of $\mathrm{T}_{\mathrm{D}}$ on spindle is by $0.03 \mathrm{sec}$ earlier then maximum elongation of housings frames due to rolling force $\mathrm{P}$. 


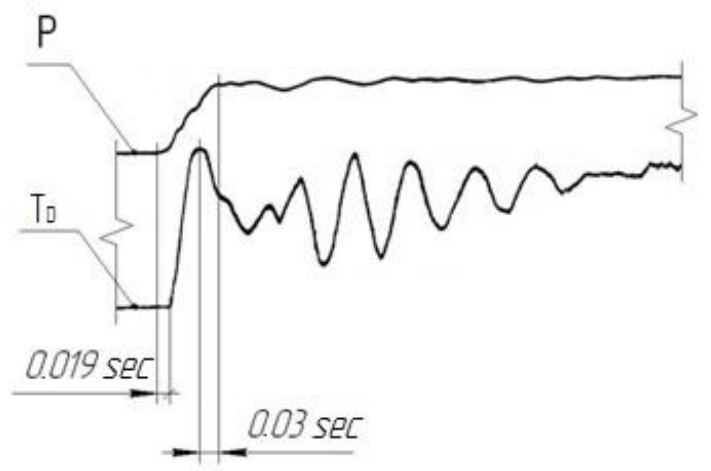

Fig. 2. Oscillogram fragment of record of rolling force $P$ and dynamic rolling torque $T_{D}$ in roughing stand of hot rolling mill 1700 .

Experimental measurements results of dynamic horizontal forces and rolling forces in roughing stand of hot rolling mill 1700 given in [10] shows that start of increase of horizontal forces $F_{H O R . I}$ acting from WR chocks on reciprocal surfaces of BURs chocks/housings is faster then start of increase of rolling force $\mathrm{P}$ by $0.01 \mathrm{sec}$ (refer to Figure 3).

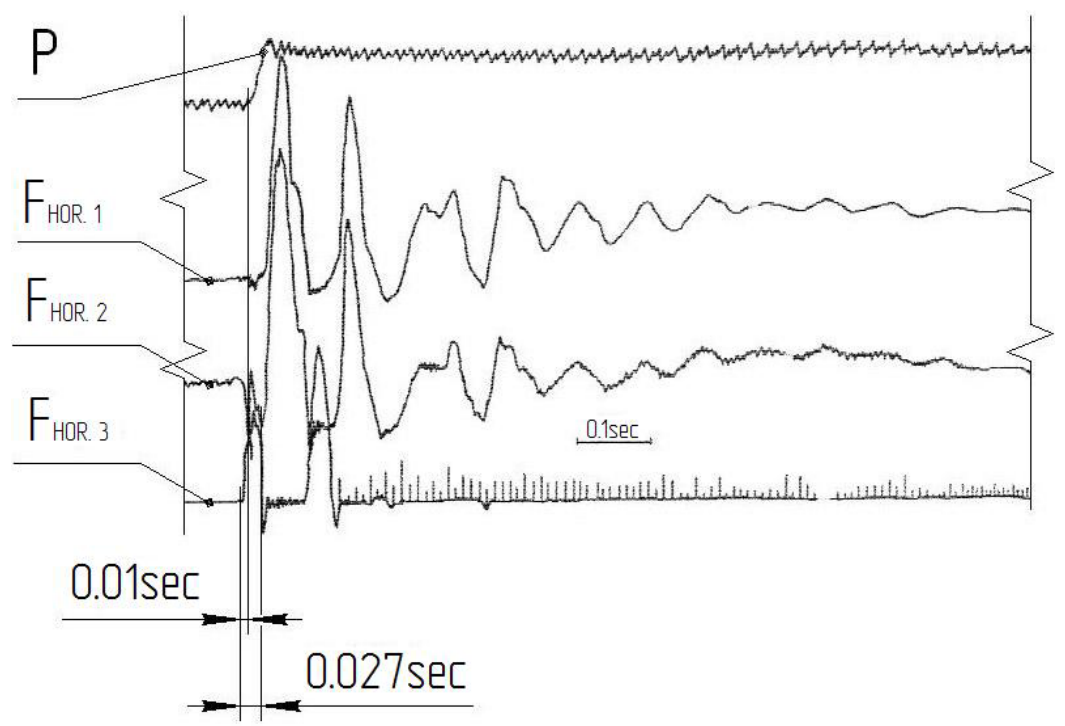

Fig. 3. Oscillogram fragment of record of horizontal forces and rolling force in roughing rolling stand of hot rolling mill 1700: $F_{\text {HOR. } 1}$ is horizontal force acting on front (in rolling direction) reciprocal lining strap of BUR chock on drive side; $\mathrm{F}_{\mathrm{HOR} .2}$ is horizontal force acting on front reciprocal lining strap of BUR chock on operator side; $\mathrm{F}_{\mathrm{HOR} .3} 3$ is horizontal force acting on back (in rolling direction) reciprocal lining strap of BUR chock on operator side.

Experimental measurements results of dynamic horizontal forces of WRs chocks impacts against housings and rolling forces in rolling stand \#5 of rolling mill 2000 given in [9] shows that start of increase of horizontal forces $F_{H O R}$. acting from WR chocks on reciprocal surfaces of housings is faster then start of increase of rolling force $\mathrm{P}$ by $0.02 \mathrm{sec}$ (refer to Figure 4). It is explained by fact [16] that sensors of dynamic horizontal forces were installed on delivery side of the rolling stand where the second WRs chocks impacts in most cases happen. 
It is experimentally proved that the first WR chocks impact against housings / BURs chocks happens on entry side [10,11]. The second impact (on delivery side of rolling stand) happens after $0.02 \ldots 0.03 \mathrm{sec}$ (refer to Figure 3) and [17] depending on design of rolling stand, gaps between contact surfaces of chocks and housings, etc.

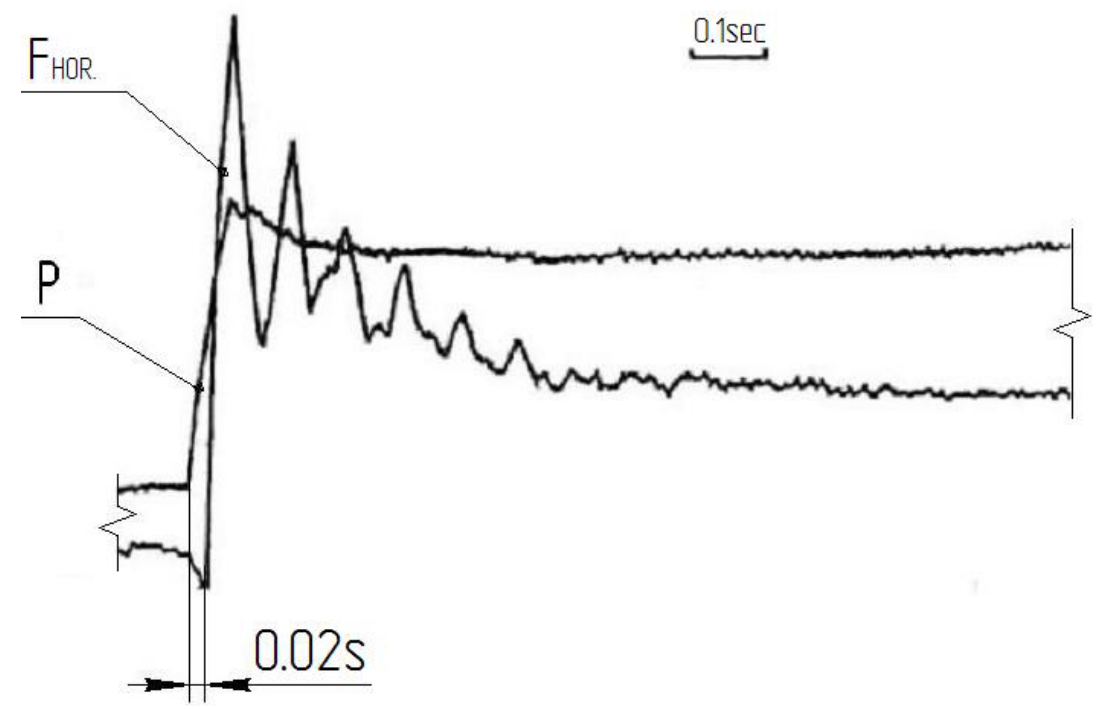

Fig. 4. Oscillogram fragment of horizontal forces of the second impact of WR chocks and rolling force in roughing rolling stand $\# 5$ of rolling mill 2000 when sensors of $F_{\text {hor. }}$ were installed on delivery side of the rolling stand.

It can be stated that $\mathrm{F}_{\text {hor. }}$ (from entry side of rolling stand) and $\mathrm{P}$ simultaneously arise for some rolling stands or start of $F_{\text {hor. }}$ increase is faster then start of increase of rolling force $P$ by around $0.01 \ldots 0.02 \mathrm{sec}$ (refer to Figure 3 and Figure 4). In addition, for theoretical calculations it can be suggested that start of $F_{\text {hor. }}$ increase is faster then start of $T_{d}$ increase by $\mathrm{t}_{1}=0.01 \mathrm{sec}$.

According to experimental loads measurements data in roughing rolling stand \#5 of rolling mill 2000 [20,22] start of $\mathrm{P}$ increase is faster then start of increase of dynamic rolling torque on motor shaft $T_{d . M}$. by $t_{2}=0.05 \ldots 0.06 \mathrm{sec}$. Start of $T_{d}$. increase is bottom spindle is faster then start of $\mathrm{T}_{\text {d. }}$. increase by $\mathrm{t}_{3}=0.014 \ldots 0.015 \mathrm{sec}$. Hence, for the roughing rolling stand \#5 of rolling mill 2000 it can be stated that start of $F_{\text {hor. }}$ increase is faster then start of $T_{d}$ increase on spindle by around $t=t_{1}+t_{2}-t_{3}=0.045 \mathrm{sec}$.

Further analysis of experimental measurements data of dynamic rolling torques on spindles, rolling forces and movements of WRs chocks is done on the basis of modern experiments.

Analysis of experimental measurements data of dynamic rolling torques on spindles and rolling forces in 4-hi thick strip rolling stand of Ilsenburger Grobblech $\mathrm{GmbH}$ [18] shows that start of $\mathrm{P}$ increase is faster then start of $\mathrm{T}_{\mathrm{d}}$ increase on spindles by around $0.027 \ldots 0.033 \mathrm{sec}$ (refer to Figure 5). In addition, $\mathrm{T}_{\mathrm{d}}$ maximum is faster than $\mathrm{P}$ maximum by around $0.045 \ldots 0.05 \mathrm{sec}$ (refer to Figure 5). 

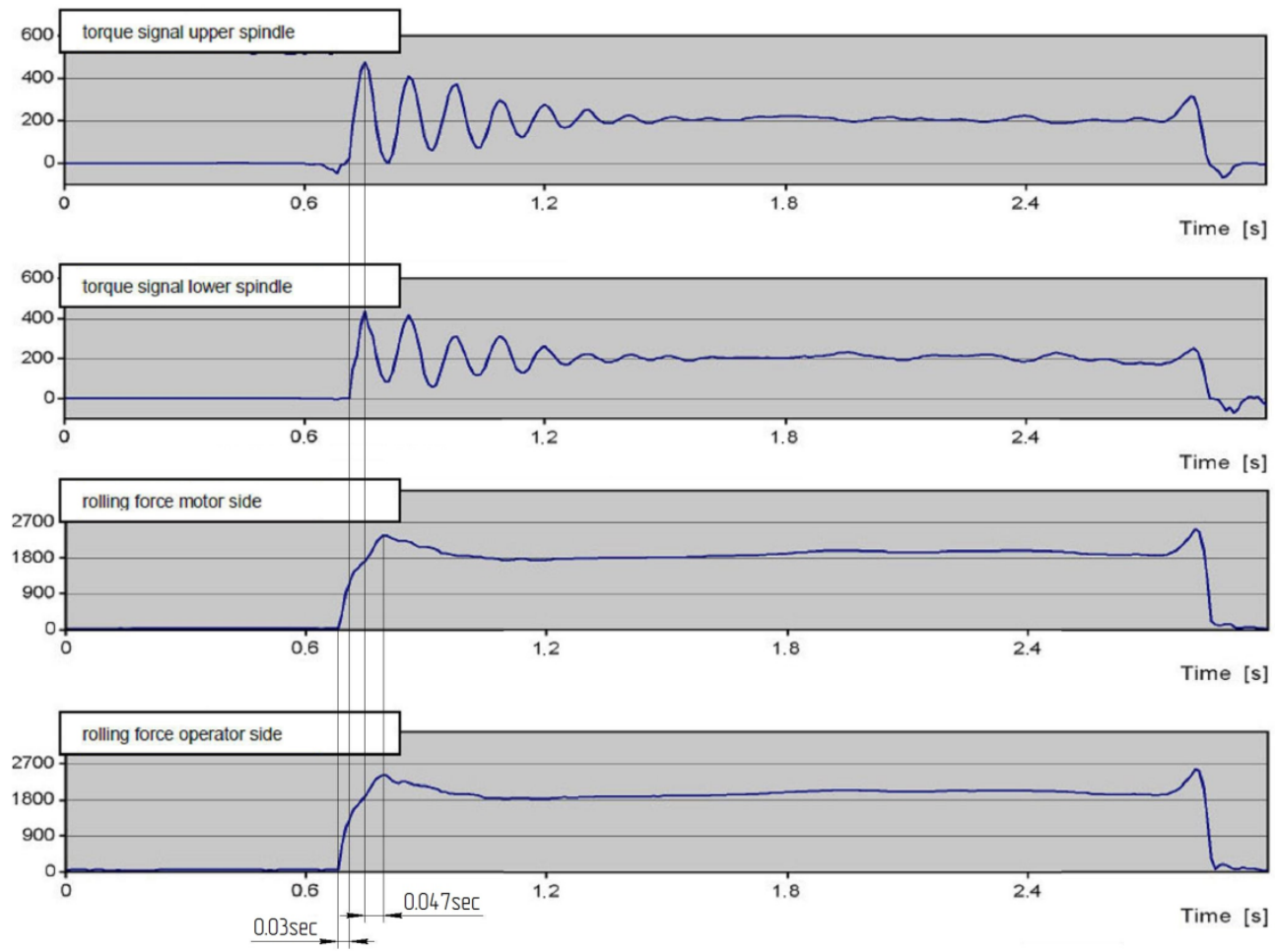

Fig. 5. Oscillogram fragment of dynamic rolling torques on spindles and rolling forces in 4-hi thick strip rolling stand.

Analysis of experimental measurements data of dynamic rolling torque on BWR spindle and rolling force in 4-hi thick strip rolling stand of Rolled Products Inc. [19] shows that start of $\mathrm{P}$ increase is faster then start of $\mathrm{T}_{\mathrm{d}}$ increase on BWR spindle by around $0.04 \ldots 0.05$ $\mathrm{sec}$ (refer to Figure 6). In addition, the second maximum of $\mathrm{T}_{\mathrm{d}}$ is faster than $\mathrm{P}$ maximum by around $1.05 \ldots 1.15 \mathrm{sec}$ (refer to Figure 6).

Analysis of experimental measurements data of dynamic rolling torque on BWR spindle $\mathrm{T}_{\mathrm{d}}$ and horizontal movements (inside housing window) of BWR chock on drive side of finishing rolling stand \#7 of rolling mill 2000 at metal bite by WRs [20] shows that start of BWR chock (on drive side) movements is faster then start of $T_{d}$ increase on BWR spindle by around $0.018 \ldots 0.024 \mathrm{sec}$ (refer to Figure 7).

Analysis of experimental measurements data done on numerous rolling stands shows that dynamic rolling torque on WR spindle starts earlier than on motor shaft [21]. 


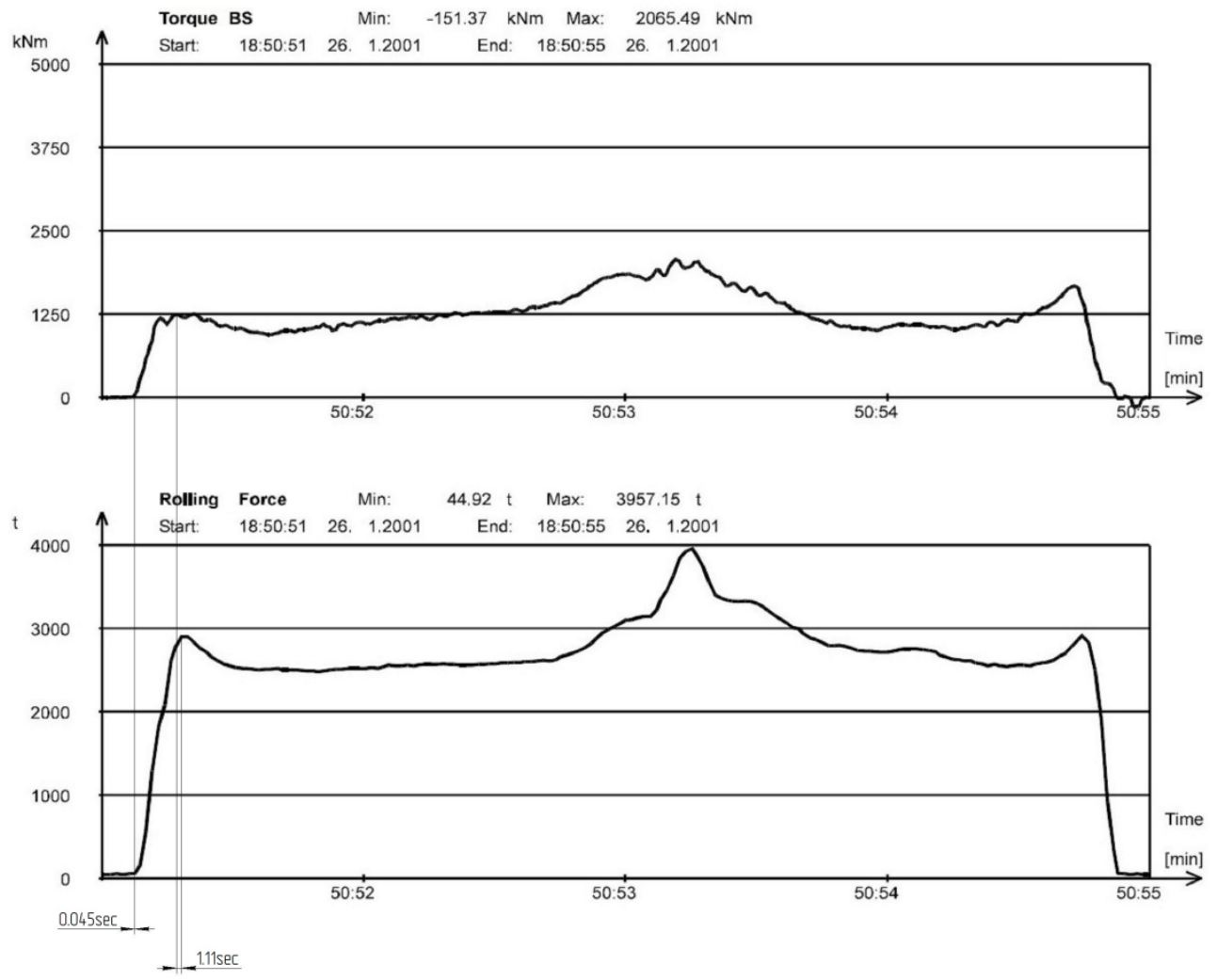

Fig. 6. Oscillogram fragment of dynamic rolling torque on BWR spindle and rolling force of 4-hi thick strip rolling stand.

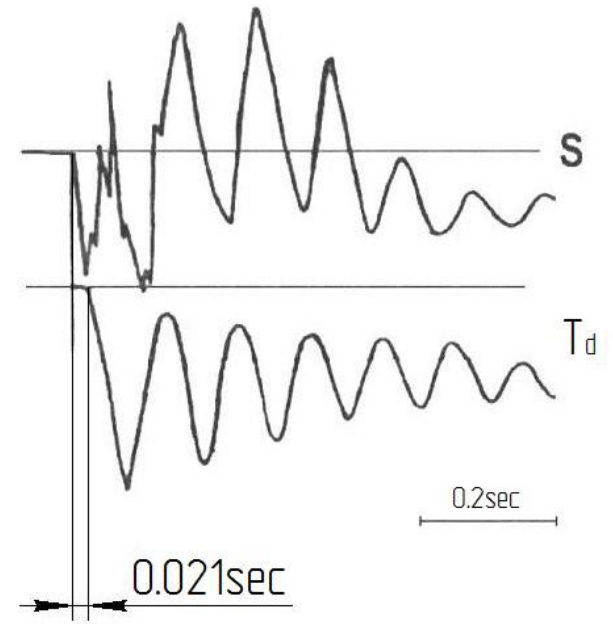

Fig. 7. Oscillogram fragment of dynamic rolling torque on BWR spindle and movements (inside housing window) of BWR chock on drive side of the finishing rolling stand \#7 of rolling mill 2000 at metal bite. 


\section{Conclusions}

1. Relations between horizontal forces, dynamic rolling torques and design of rolling stands are shown for 4-hi rolling stands.

2. Based on numerous experimental data it is proved that horizontal inertia forces acting on WRs and transformed in dynamic horizontal forces of WRs impacts against housings (slots of BURs chocks) at metal bite arise earlier than dynamic rolling torque on WRs spindles. It states necessity to consider the dynamic horizontal forces during rolling.

3. Theoretical and experimental analyzes are done which state that starts of horizontal impacts of WRs chocks against housings (slots of BURs chocks) are earlier than starts of dynamic rolling torque on WRs spindles by:

- $\quad 0.03 \mathrm{sec}$ for the roughing rolling stand of rolling mill 1700 ;

- $\quad 0.045 \mathrm{sec}$ for the roughing rolling stand \#5 of rolling mill 2000;

- $\quad 0.021 \mathrm{sec}$ for the finishing rolling stand \#7 of rolling mill 2000.

4. Horizontal forces of WRs impacts against housings (slots of BURs cocks) at metal bite arise earlier than other forces/loads responsible for accidental breakdowns of rolling stands equipment. Hence, the horizontal forces should be considered and controlled for increase of rolling stands durability.

\section{Acknowledgments}

The reported study was funded by RFBR according to the research project №16-08-00845a «Verification and development of models of inelastic deformation at the passive loading». The authors declare that there is no conflict of interest regarding the publication of this paper.

\section{References}

1. V. Mazur, V. Artyukh, G. Artyukh, M. Takadzhi, Engineering Designer 37(1), 26-29 (2012)

2. E. Sorochan, V. Artiukh, B. Melnikov, T. Raimberdiyev, MATEC, 73, 04009 (2016)

3. R.S. Adamiya, Optimizaciya dinamicheskikh nagrusok prokatnikh stanov (Metallurgy, Moscow, 1978)

4. M.F. Firas Al-Quran, M.E. Matarneh, V.G. Artukh, Research Journal of Applied Sciences, Engineering and Technology 4(11), 1585-1589 (2012)

5. V.G. Artiukh, S.Yu. Karlushin, E.N. Sorochan, Procedia Engineering 117, 938-944 (2015)

6. V.I. Bolshakov, Metallurgical and Mining Industry 4, 72-78 (2000)

7. V. Artiukh, V. Mazur, E. Pokrovskaya, MATEC, 86, 01030 (2016)

8. V. Artiukh, V. Mazur, R. Prakash, Solid State Phenomena 871, 3-8 (2016)

9. S.D. Garzman, Collection of scientific papers, 137-140 (1980)

10. V.D. Plakhtin, Universities News: Ferrous Metallurgy 10, 36-37 (1983)

11. A.A. Ishenko, Steel 5, 56-58 (2009)

12. T. Usugy, Universities News: Ferrous Metallurgy 6, 52-55 (2005)

13. V. Mazur, V. Artiukh, M.I. Matarneh, Procedia Engineering 165, 1722-1730 (2016)

14. V.G. Artiukh, Steel 7, 64-66 (2011) 
15. M.I. Matarneh, N.S. Gharaibeh, V.G. Artyukh. IJESIT 4(2), 1-7 (2015)

16. V. Artiukh, T. Raimberdiyev, V. Mazur, MATEC, 53, 01039 (2016)

17. A.A. Ishenko, Issledovanie dinamicheskikh nagrusok na stanini kleti stana $3000 v$ processe prokatki i rasrabotka predlozeniy po optimizacii ego raboti (PSTU, Mariupol, 2006)

18. R. Krumbach, Developing a Report Generator for the Automatic Analysis of Rolling Data in Heavy Plate Mills (RWTH, Aachen, 2001)

19. Report on Measurements and Process Analyses at the Heavy Plate Mill of Rolled Products Inc. (USA, ACIDA Gmbh, 2004)

20. V.V. Verenyov, Diagnostica $i$ dinamika prokatnikh stanos (IMA-press, Dnepropetrovsk, 2007)

21. V.V. Verenyov, Dinamicheskiye processi v kletyakh shirokopolosnogo stana 1680 (IMA-press, Dnepropetrovsk, 2011)

22. N.S. Gharaibeh, M.I. Matarneh, V.G. Artyukh, Research Journal of Applied Sciences, Engineering and Technology 8(12), 1461-1464 (2008) 